\title{
AZV, vida de la crítica y crítica de la vida
}

Jorge Urrutia ${ }^{1}$

Recibido: 27 de febrero de 2017 / Aceptado: 4 de octubre de 2017

Resumen. Este ensayo busca exponer la originalidad del gran dialectólogo, crítico literario y escritor Alonso Zamora Vicente desde la relación de la persona y obra. Sin duda es el concepto de la vida y de la sociedad el que ilumina tanto su obra erudita como crítica o creativa, cuestionando así las prácticas no experienciales.

Palabras clave: Alonso Zamora Vicente; crítica literaria; dialectología española; Ramón del Valle Inclán.

\section{[en] AZV, The Life of Critics and The Critique of Life}

\begin{abstract}
This essay seeks to explain the originality of the great dialectologist, literary critic and writer Alonso Zamora Vicente from a life and work perspective. The concept of life and society is what undoubtedly enlightens both his erudite and critical or creative work, thus questioning non-experiential practices.
\end{abstract}

Keywords: Alonso Zamora Vicente; Literary Critic; Spanish dialectology; Ramón del Valle Inclán.

Sumario: 1. Presentación; 2. AZV y las gentes; 3. AZV y la crítica; 4. Referencias bibliográficas.

Cómo citar: Urrutia, J. (2017). AZV, vida de la crítica y crítica de la vida, en Revista de Filología Románica 34. Núm. especial, 133-141.

\section{Presentación}

No me resulta fácil hablar de Alonso Zamora Vicente. Ya hace años escribí sobre su obra, cuando preparé un número especial de la revista Papeles de Son Armadans $(1973)^{2}$. Lo siento aún muy próximo, como si fuese a aparecer ahora mismo por

1 Catedrático emérito de la Universidad Carlos III de Madrid

Email: jorge.urrutia@uc3m.es

2 Papeles de Son Armadans, tomo LXX, núms. CCIX-CCX, 1973. Contiene colaboraciones de Camilo José Cela, Dámaso Alonso, María Josefa Canellada, Francisco Marcos Marín, Jorge Urrutia, Emilia de Zuleta, Charles V. Aubrun, José Antonio Cáceres, Manuel Ariza, Marcel Bataillon, Antonio Prieto, Ángel R. Fernández, Tomás Navarro Tomás, Francisco Ynduráin, Jorge Guillén, José García Nieto, Ramón de Garciasol, Leopoldo de Luis, Ruy Belo, José Manuel Blecua, Jorge C. Trulock, Rafael Lapesa, Pilar Vázquez Cuesta, Emilio Alarcos Llorach, Manuel Alvar, Daniel Devoto, Frida Weber de Kurlat, Horst Baader, María Berta Pallares de R. Arias, Manuel Bermejo Marcos, Elías L. Rivers, Fernando Lázaro Carreter, Ian Michel, Carmen Martín Gaite. Cubierta de John Ulbricht y retrato de Martínez Novillo. 
aquella puerta del fondo. Fueron años a su lado, acostumbrado a encontrarme con él, a escuchar su voz al otro lado del teléfono, a saber, que ante el sofá de su casa de la calle Pez Austral o de la Real Academia me esperaban un café y algunas galletas hechas por María Josefa Canellada. "Os dejo - decía ésta- para que habléis de vuestras cosas", como si no pudieran ser también las suyas.

Fueron muchos años de proximidad -digo- pero no a la manera de uno de esos perritos acostados a los pies de las tumbas renacentistas, sino con una amistad cordial, sin apenas fisuras más que las que el trato habitual puede producir. Fueron, sobre todo, muchos años de magisterio (¿es que el verdadero magisterio puede prescindir de la amistad?), un magisterio mantenido incluso a distancia, de frecuentes conversaciones, de muchos paseos arriba y abajo por las calles de Madrid, esa ciudad que tan bien conocía y cuyo subdialecto estudiase en el ensayo "Una mirada al hablar madrileño" (Zamora Vicente 1966). Es un habla que -explicaba- respondió a "la vida oscura de las clases populares" en la encrucijada de los siglos XIX y XX, que acentuaba "la valía de unos cuantos sentimientos nobilísimos [...] en contraste con los apuros que las transformaciones económicas iban provocando". Fue un magisterio, el de Alonso Zamora, en el que me reconozco. De él aprendí literatura y lingüística, claro es, pero creo preferible medir el magisterio por los intangibles: el modo de encarar la profesión, la forma de dirigirse a los estudiantes, la necesaria relativización de las normas académicas, la consideración de los demás, el interés por las gentes sencillas, el amor por lo popular. ¡Cuántos viajes hicimos por los alfares de Toledo, pacenses, sevillanos! ¡Cuántos huevos fritos con patatas comimos en pequeños, a veces miserables, bares de pueblo! ¡Cuántas charlas sonrientes o serias con las gentes que encontrábamos en unos u otros lugares!

El 28 de mayo de 1967 leyó su discurso de ingreso en la Real Academia Española don Alonso Zamora Vicente ${ }^{3}$. Yo era por entonces alumno suyo, en la asignatura de Dialectología Española, pero lo había conocido un año antes, cuando se presentaron Pascua y Naranjas, de Manuel Vicent, y Travesía de Madrid, de Francisco Umbral, novelas ganadora y finalista del Premio Alfaguara, editorial fundada poco antes por el también académico, y amigo de don Alonso, Camilo José Cela. Fue el poeta Ramón de Garciasol quien me presentó a Zamora Vicente. Éste se interesó por lo que yo hacía y me habló de la importancia del estudio filológico. Confieso que me cautivó la bonhomía y el humor de don Alonso, su sencillez y su capacidad de escuchar. Ya había yo descubierto que escuchar no suele ser práctica común entre los españoles. Cabe decir, pues, que era un español excepcional.

En su clase de Dialectología Española no faltaban las amplias digresiones por las culturas populares, desde las técnicas alfareras al modo de fabricar una pelota de frontón. La filología se incardinaba en el pueblo, como ya me había insinuado la tarde en que lo conocí en aquel salón de la empresa Huarte, en pleno paseo madrileño de la Castellana que, a esa altura, se llamaba Avenida del Generalísimo. Para los que fuimos niños en el Madrid de los años cincuenta, aquello era el principio de Corea, es decir, de las primeras calles de la zona donde se habían ido a vivir muchos militares norteamericanos. Pero volvamos a lo nuestro; ya dice el refrán que "ni todo es para dicho, ni todo para callado". Los estudiantes de la Facultad es muy posible que pensasen que el profesor tenía nombre y apellidos de principio de equipo de fút-

3 Cito de la primera edición en diferentes ocasiones. 
bol: Alonso Zamora Vicente. Casi el portero y dos defensas del Real Madrid. La broma no es mía, es de Jorge Cela Trulock, pero se la tomo en préstamo. Inicio de alineación o no, el aula de Dialectología era un territorio lleno de ríos, montañas, ganados, campesinos y canciones. Era esa España rural que, con el eco de la búsqueda de romances junto a Ramón Menéndez Pidal, se dibujaba por la palabra de don Alonso, frente a los paisajes velazqueños de la ciudad universitaria madrileña. Por primera vez, como en un milagro, la experiencia campesina familiar de los alumnos durante el verano cobraba valor cultural y las palabras maternas entraban en el aula.

El caso es que yo no podía faltar en el salón de actos de la Real Academia Española aquel 28 de mayo. Y no lo hice. Aprecié una vez más el verbo fluido y elegante del nuevo académico, su ironía y su deseo de entender y de aclarar la obra literaria. Y había razones para apreciarlo.

Cuando uno echa la vista atrás, Alonso Zamora Vicente pudiera ser un personaje literario. No, no se crea que pienso en la obra de Ramón del Valle-Inclán; de ninguna manera. No hubo en don Alonso carácter esperpéntico alguno, por mucho que estudiase Luces de Bohemia. Uno espera, eso sí, verlo surgir, por las esquinas de una novela galdosiana; tal vez pudiera ser aquel intelectual curioso que conversa con Nazarín al principio de la narración. Un personaje que adelanta palabras que bien pudieran haber sido escritas por don Alonso para que precedieran sus cuentos: "yo mismo - leemos en Pérez Galdós- me vería muy confuso si tratara de determinar quién ha escrito lo que escribo. [...] La narración, nutrida de sentimiento de las cosas y de histórica verdad, se manifiesta en sí misma, clara, precisa, sincera". También pudiera haberse transformado Zamora Vicente en la persona sensata que pone paz, allí, por la calle de los Mancebos o en Nueva Numancia, dentro de alguna narración madrileñista como El patio de Monipodio. "Era prudente sin debilidad -explica de su personaje Fernando Mora-, firme sin violencia, político sin bajeza, y no dejó nunca de cortar sus uñas y de afeitarse por lo menos tres veces por semana, pues así lo tenía ordenado el Reglamento en sus primeros capítulos. Baste para completar el retrato [...] añadir que era su cutis moreno, aventajada estatura, de negros y brillantes ojos y que más parecía destinado a vestir elegancias que un negro traje...".

\section{AZV y las gentes modestas}

Nazarín, El patio de Monipodio..., novelas por las que transitan gentes simples, inocentes o malvadas, pero en todo caso artífices de un mal de poca monta, más de envidias que de corrupciones, más de pelea doméstica que de grandes batallas, sufridores de lo cotidiano, supervivientes del transcurrir del tiempo. Alonso Zamora Vicente me enseñó a sentir a esas gentes modestas, por las que siempre acaba desbordándole a uno el cariño o la compasión. Como él, nací en un barrio de Madrid. Me reconozco en ese hablar madrileño que, como escribía Zamora, "en la actualidad, por la enorme nivelación idiomática (el cine, la radio, la televisión, el más alto nivel cultural, etc.), va relegándose a manifestaciones cada vez más localizadas, $\mathrm{y}$, desde luego, sin la aguda punzada con que aparecía aún no hace muchos años".

Mi padre no dejó que las calles me absorbieran, evitó que yo cayese en la vulgaridad, procuró que respirase el aire de la cultura. Me hablaba de los grandes poetas, 
me llevaba a los museos, veíamos y me explicaba el teatro clásico. Don Alonso, en cambio, llegó para hacerme descubrir el viento del pueblo, el placer del objeto diario, la maravilla del telar o del torno. Con él me percaté del yeísmo, de la aspiración madrileña de la $-\mathrm{s}$ trabante en doh pareh, o en ehtaremoh; de su nasalización, yo mimmo; de la articulación tensa hasta la geminación de ciertas consonantes, ;anndda ya!; del golpeteo de metralleta que produce la entonación madrileña: ¡KKettekkres tú eso! Mi padre me había entregado la cultura, Zamora Vicente ponía en mi mano lo popular y el sentido común. Sé que esto puede llamarles la atención: un gran profesor me enseñó la vida de todos los días. Pero fue así.

Ello resultó para mí muy importante. Porque yo estaba condenado a mitificar la cultura erudita y Zamora supo hacerme ver que la erudición hay que tenerla, pero no exhibirla. Me lo decía una y otra vez, y yo lo comprendo bien ahora, al final de mi vida académica: no hay nada más temible que un profesor pedante empeñado en demostrar a todas horas cuánto sabe. Y me viene a la memoria una frase que don Alonso repetía. "Prefiero la decencia a la docencia". A un profesor decente se le puede enseñar, un profesor indecente es incorregible.

En un texto leído en la Universidad Menéndez Pelayo de Santander, en 1968, don Alonso hablaba de esa gente que yo aprendí en gran parte a individualizar y a amar con él (Zamora Vicente 1969). Supo, con una enumeración digna del torrente de conciencia de James Joyce -que él leyó muy temprano-, pero pasándolo por el tamiz del sentimiento, como su condiscípulo Camilo José Cela, atravesar de sentimiento la narración conductista:

\begin{abstract}
Son los míos, los que me recuerdan que no estoy solo, y quizás también los que van escoltando el inevitable deslizamiento hacia la radical soledad [...]. La cantante loca, el poeta que recita como propios los versos ajenos, la burguesita de pueblo que ha presenciado un accidente en la carretera y dice sandeces monumentales, la monja bobalicona que enseña preces e ignora el teorema de Pitágoras, y el albañil que, de vuelta de una paella en el pinar sucio de los alrededores, canta Asturias, patria querida hasta enronquecer, y el ye-yé pitongo que repatea palabrejas en inglés y se mira al espejo imitando a Elvis Presley o a Richard Anthony, y la mocosuela que no sabe aún fumar ni llevar la falda brevecilla, y la pensionista que siempre está si mi difunto levantara la cabeza, y el hombre importante que tiene influencias en los ministerios y puede auxiliar a los calzonazos que andan de oposiciones, que los buenos ya se las arreglarán como puedan, y el que se cuela en las colas silbandillo, y la pobre mujer que cose a domicilio, cada vez más roídos los puños de piel, más torcidos los tacones... Y todos. Todos envueltos en esta niebla de opaca, soñolienta tristeza. Ah, no, no me gustan nada. Absolutamente nada. Pero los quiero. Son los míos, los que tengo ahí. Dios no me ha dado otra España más habitable y debo resolvérmela todas las mañanas (Zamora Vicente 1969:285).
\end{abstract}

Yo, por mi parte, recuerdo a Doroteo, el frutero de debajo de mi casa, y al zapatero remendón que un día nos compró el piso. Recuerdo a Matías, el tendero, y a Justo, su sobrino, separando a dos que se pegaban a la puerta de una taberna tras haberse estampado uno a otro una botella en la cabeza. Veo aún brillar la sangre por la frente y la acera. Recuerdo al viejecillo cegato que cambiaba tebeos y novelas por 25 céntimos de peseta, a Apolonia, la portera, que llamaba Polín a mi padre y no don Leopoldo, al cartero que repartía las cartas en el portal. Recuerdo a la lechera que ofrecía litros de leche a distintos precios según el agua que contenía. Gente trabaja- 
dora que vivía de milagro, que había sufrido el cerco de la ciudad durante tres años, y permanecía en silencio, comprando dos pesetas de aceite, medio litro de leche impura, doscientos gramos de carne picada - ¡cualquiera sabe qué carne!-, media barra de pan oscuro. Y escucho a Luis, el carpintero de arriba de mi casa, que serraba la madera para el mueble que fabricaba, mientras yo pretendía dormir en un pequeño cuarto oscuro y compartido. Más tarde, conocí a aquella señora, más ancha que alta, con una cicatriz en la mejilla izquierda, que salió un tiempo en televisión anunciando un detergente que lavaba más blanco, como aseguraba ella desde la pantalla. En el barrio la llamábamos "la actriz" y la actriz se sentaba en una silla de anea, al caer la tarde de verano, al pie de la acera, en la esquina de Jerónima Llorente con Fray Hortensio Paravicino, de quienes nadie, más allá de mi abuelo, sabía nada en el barrio. Jerónima Llorente, una actriz romántica que tuvo que dejar los escenarios cuando perdió toda la dentadura, como alguna de esas mujeres que ahora conversan, gozando la brisa del anochecer madrileño, con "la actriz" del detergente. Paravicino, un orador sagrado que se elevaba del mundo a las alturas, pero poeta barroco a quien retratase El Greco. Ambos llevados a unas calles modestas y simples, reales como lo es la vida, habitadas por estas gentes mías que viven la memoria de la desmemoria. Pero no está todo tan distante, pues según escribió Fray Hortensio en un soneto, "Aquí es verdad la secta, y aquí hallara / del cielo ese fatal desasosiego". Todas gentes sencillas, simples, silenciosas o parlanchinas, con escasas pretensiones y una esperanza oculta, casi perdida, entre las telas que les cubrían el pecho. Similares a las que don Alonso frecuentó en su barrio del viejo Madrid y cuyo eco llevaba al instituto San Isidro, cuando iba a examinarse a fin de curso. El mismo instituto de mis reválidas, con sus muros anchísimos de piedra, sus largos corredores y su frío. Fue fácil que yo amase los personajes de Zamora Vicente porque fueron los míos, los que jalonaron mi infancia en el tranvía y en el metro, en la tienda de ultramarinos y en la lechería. También puedo decir, como él, que están "todos envueltos en esta niebla de opaca, soñolienta tristeza. [...] Pero los quiero. Son los míos". En sus cuentos, hablan sin parar, con una verborrea inquietante y propia. Por eso el autor podía confesar que no sabía bien quién escribió lo que escribiera.

Hablaba de todo ello Alonso Zamora Vicente en la Universidad Menéndez Pelayo en agosto de 1968. Lo escuché decir, recién acabada mi licenciatura, camino ya de mi pequeño exilio, "Yo escribo los domingos", por eso, escritor festivo, escritor de los días de fiesta, observaba que, entre los escritores profesionales, "estoy aquí con menos derecho que nadie. [...] Es verdad que escribo, sí", pero "estoy ya condenado a ser un escritor [...] de domingo. Santifico la fiesta a mi modo, escribiendo un poquillo, tarde de domingo arriba [...] como un tranquilo jornalero". Un tranquilo jornalero... Don Alonso, como aquel personaje de la novela madrileñista de Fernando Mora, era firme sin violencia y político sin bajeza. Decía, pues, lo justo y justo. El filósofo Jacques Rancière tiene un libro titulado La noche de los proletarios (2010) (Urrutia 2015) ${ }^{4}$. Se refiere en él, y lo he desarrollado yo mismo en otra parte, a aquellos obreros que, a la hora en la que los demás descansan o se divierten, prefieren hacer literatura o arte o política. Son gentes de las que no se piensa

$4 \quad$ La noche de los proletarios es un libro que utilizo en varias ocasiones para los ensayos de mi libro Juguetes de un dios frio. Literatura, historia, ideología (Urrutia 2015). 
que puedan dedicarse a tales ocupaciones y, por ello, su producción apenas si se considera. Jornaleros de sus trabajos, prosiguen la jornada como noctívagos de la literatura. Olvidados de todos, o despreciados por quienes opinan que cada cual debe quedarse en su sitio, es decir, en el sitio que ellos pretenden para los otros.

Don Alonso observaba en su intervención de la Menéndez Pelayo, que también los escritores querían que él se dedicase sólo a la crítica, de una vez. Pero los profesores entendían que mejor debería pasar su tiempo escribiendo cuentos. Unos y otros hubieran preferido que los domingos hubiese tenido la costumbre de irse al cine, o al fútbol, o a pasear por la acera oeste del Paseo del Pintor Rosales. Unos y otros, los que pretenden la literatura como una distinción (¡Ay, Pierre Bourdieu, qué poco has entendido!), preferían que Zamora Vicente se alejase, porque era un disidente, alguien que defendía su propia vocación y quería actuar según su propio sentido de la responsabilidad. Hacer lo que era preciso hacer en cada instante. Esto también supo enseñárnoslo. Y lo enseñaba con su vida, con su docencia, con su crítica literaria.

\section{AZV, crítico literario}

Detengámonos ante aquello que encontré de novedoso en el discurso de ingreso de Alonso Zamora Vicente en la Real Academia Española. Pretendo referirme a las diferencias que hallé con respecto a lo que escuchaba durante las clases universitarias de literatura o de lo leído en los libros de crítica recomendados en la bibliografía. Y lo primero que noté fue un tono distinto. Un tono que correspondía a un compromiso con el texto estudiado. Debo indicar que la locura de la universidad española de aquellos años hacía que muchos profesores no enseñasen aquello que uno hubiera esperado y deseado. Un ejemplo sintomático es que lunes, miércoles y viernes, a las nueve de la mañana, don Dámaso Alonso nos explicaba Lingüística Románica y luego, a las diez, aparecía un joven profesor, que llegaría a importante fonetista aunque muriese pronto, para explicar el sistema crítico de Dámaso Alonso. Más tarde, otro catedrático, que tenía la costumbre de llegar un cuarto de hora tarde, costumbre compensada, eso sí, con el hábito de salir un cuarto de hora antes, convertía la literatura - pese a sus amplios conocimientos- en una suma de fechas y nombres acompañada por maledicencias sobre sus antecesores, desde Menéndez Pelayo hasta Américo Castro. Viene todo esto a cuento para que quede claro por qué la palabra amorosamente interpretativa de Alonso Zamora Vicente resultaba una novedad casi estremecedora.

El nuevo académico no optaba por un enfrentamiento frío, aséptico, con la obra. Tampoco mostraba un amor desmedido por el autor, ese amor que tantas veces oscurece el sentido crítico. Comprendíamos, sentados en el gran salón académico, que una obra literaria puede entenderse sintiéndose el analista unido con ella para, desde la comprensión, explicarla. ¿Cuándo confesaremos que la primera función del profesor, y muy posiblemente del crítico, es hacer comprender la obra literaria? Aquella redirección de la crítica hacia la experiencia personal no resultaba, curiosamente, extemporánea cuando llegaban ya a España los ecos de las poéticas formalistas. Recuerdo la insistencia con que don Alonso me pidió que le trajera de Francia, a una de cuyas universidades me incorporé poco después de acabar la licenciatura, un ejemplar de la Introduction à la grammaire générative, de Nicolas Ruwet, que acababa de publicarse en 1968. 
En su discurso académico, respirando el mismo aire, venía a adelantarse a lo que Roland Barthes teorizase en su ensayo "Par où commencer?" $(1974)^{5}$, apertura de la que fue importante revista Poétique:

El trabajo [crítico] no puede consistir [...] en partir de las formas para percibir, aclarar o formular contenidos [...], sino, por el contrario, en disipar, retroceder, desmultiplicar, poner en marcha los primeros contenidos bajo la acción de una ciencia formal. [Consiste en] comenzar el análisis a partir de algunos códigos familiares y del derecho de abandonar estos códigos (transformarlos), avanzando, no en el interior del texto [...] sino en el interior del propio trabajo (Barthes 1974).

No se trataba, en el estudio que don Alonso hacía de Luces de Bohemia, de una crítica impresionista o básicamente erudita, tampoco de un estudio formalista pleno; ensayaba, sin confesarlo, una metodología de corte semiótico que se basaba en los significados y en los valores de los signos. Lo que importaba era descubrir, no tanto lo que exteriorizaba el significante, sino lo que, en virtud de la contextualización, escondía y, para ello, el crítico puso en el tablero su propia experiencia vital. Referirse a la experiencia no pretendía exponer coincidencia existencial alguna, sino aclarar la significación de los signos al situarlos en su contexto histórico. Buscaba evidenciar el significante para remover lo simbolizado. El valor de la literatura no está tanto en lo que muestra, sino en lo que esconde. Así, se refiere a los espejos modernistas que son recuperados por Ramón del Valle-Inclán y que, en Luces de Bohemia, se manifiestan a través de aquellos deformantes, cóncavos y convexos, que un comercio puso en su fachada del callejón madrileño dedicado al poeta renacentista Juan Álvarez Gato, aquel que escribiera: "Y lo más disimulado / aquello es lo que se quiere". En los espejos de su calle se miró don Alonso de niño, como nos hemos mirado todos los niños madrileños, pues allí siguen los espejos, al frente de una ferretería, antes, de un establecimiento de bebidas, ahora. La deformación de los espejos sirve al dramaturgo para construir la imagen de una realidad que espera que se perciba sorprendente, imposible, o difícil de creer y, desde luego, arduo de aceptar. Porque hay en la elección de Valle-Inclán una clara voluntad de estilo, es decir, de situarse en el mundo por medio de su lenguaje literario. De ahí estas frases espigadas, aquí y allá, por Alonso Zamora entre las obras del autor: "España es una deformación grotesca de la civilización europea"; o bien: "Deformemos la expresión en el mismo espejo que nos deforma las caras y toda la vida miserable de España". ¿Pero cuál es el resultado de deformar lo que ya deformó el espejo? ¿Una deformación grotesca? "Y lo más disimulado / aquello es lo que se quiere", decía el poeta madrileño Álvarez Gato. En lo que esconde, y no en lo que muestra, radica el valor de la literatura.

Los espejos cumplen su función, aquella para la que fueron fabricados: reflejan. Si la deformación perteneciera al espejo, si fuese producida por su superficie, no tendría mayor importancia. Pero distinto es si la deformación estuviera ya en el objeto reflejado. De ahí que Zamora comprenda que no se hace crítica literaria al limitarse a hablar de los espejos del callejón del Gato, e insista en que hay que ir más allá, porque, si los espejos nos dan "una súbita luz sobre la deformación grotesca

$5 \quad$ Ensayo de Roland Barthes (1974: 59-70). Cito por esta edición en varias ocasiones. 
[...], no puede proyectarse sobre la deformación misma”. ¿Reflejo deformante o reflejo de lo deforme? Resulta, pues, posible entender la teoría de los espejos esperpénticos, más como reafirmación de aquella que ejemplificó Stendhal en Rojo y negro, cuando se refirió al espejo situado al borde del camino, que como su negación. Porque -y aquí hablo yo, que no Zamora Vicente- Stendhal explica que el espejo puede reflejar tanto el azul del cielo como el cieno del sendero, y el novelista que lleva consigo el espejo no tiene responsabilidad alguna en si había o no barro en la vereda. Estamos ante la metáfora del realismo.

Valle-Inclán retrata personajes insólitos del Madrid de comienzos del siglo XX que Alonso Zamora va desgranando uno a uno, descubiertos tras la vestimenta de palabras con la que los recubre el dramaturgo. Como personajes, se construyen a partir de la literatura paródica, del género chico, de los espectáculos de arrabal, de las características de los escenarios, de las caricaturas de las revistas cómicas o de los periódicos de crítica política. El académico recuerda en su discurso lo vivido, lo leído, lo escuchado en la familia o en el barrio. Barthes se refería a "comenzar el análisis a partir de algunos códigos familiares". Su hacer de lector, la propia arquitectura cultural que lo define como sujeto lector (que diríamos cursimente en clase), se vuelca sobre el enunciado para extraer la significación del texto, porque Valle, más que inventar, construye con los elementos de que dispone, muchos de ellos materiales de desecho y formas del subdialecto madrileño, al que Zamora dedicaría, por cierto, un precioso ensayo. Y lo hace con citas literarias a veces casi mostrencas, bromas populares, canciones, fragmentos teatrales de bulevar, versos de zarzuela... Los espejos planos, que también los hay en el callejón de Álvarez Gato, se curvan para dejar en toda su evidencia las malformaciones de la vida. Porque los niños no juegan a mirarse tan sólo en los espejos cóncavo y convexo junto al escaparate, sino que pasan del plano al cóncavo y de éste al otro espejo plano y luego al convexo, y vuelta a empezar. Piensan: "yo soy yo, pero también soy esto que aquí veo, gordo y hecho un tapón, o altísimo y escuchimizado". La realidad tiene su doctor Jekyll, pero también su señor Hyde, como fijara para la historia Robert Louis Stevenson en 1886, cuando Valle-Inclán tenía 20 años.

La crítica resulta imposible si el estudioso permanece exclusivamente en los saberes más exquisitos. Aquella tarde de mayo, el nuevo académico, nos descubría, no que en el enunciado había más o menos anáforas, una lítotes, cierto políptoton y alguna homeóptote o paronomasia. La obra literaria no era para él una plantación por donde recolectar figuras retóricas. Menos todavía una sucesión de anécdotas. Tampoco se trataba de llevar adelante una discusión genérica ni de enfrentar la obra con otras anteriores que hubieran servido de fuente. La crítica de fontanería, que decía Pedro Salinas. Alonso Zamora Vicente descubría cómo se construyó Luces de Bohemia y buscaba hacer, para y con nosotros, el camino inverso. Es decir, buscaba reconvertir en vida la obra literaria ¿Y si la literatura no es vida, qué otra cosa puede ser? De ahí el cariño que mostraba el estudioso. Un cariño que no impide ni el disentimiento ni la reconvención. Simplemente permite o facilita el acercamiento comprensivo. Dijo aquel día el maestro que, entretejida con todas las aparentes excentricidades, yace en el drama de Valle-Inclán "la realidad de una vida difícil, empobrecida y soñadora". Por eso, al referirnos al esperpento, "no hablemos más de deformación. En todo caso, de lección avisadora". Una lección que se elabora al situar en un orden preciso los elementos seleccionados. Lo que Valle pone de manifiesto es la propia deformación de cierta realidad española. 
Toda la vida, pues, fluye por la obra de Valle-Inclán y Alonso Zamora nos enseñaba en su discurso de ingreso, aquella primavera de 1967, que no todos los saberes necesarios para el estudio de la literatura se encuentran en los manuales, en las enciclopedias o en los diccionarios. Ni siquiera en las bibliotecas habituales de referencia. Hay que acudir a la vida, a las gentes que recorren las calles o trabajan en el campo, a aquellas personas que precisan una chaqueta nueva, una medicina demasiado cara, un pequeño empujoncillo para ascender. Y así, literatura propia de creación y crítica literaria se funden en la mirada que el escritor dominguero y el crítico dirigen sobre la realidad. Y el eco de esa preocupación cotidiana resuena en el aula.

Con el recuerdo vivo de Alonso Zamora Vicente andamos, renqueando, trastabillando, descomponiéndonos. Porque no tenemos su capacidad, su clarividencia, su valor ni su saber. Aprendimos de su mano filología, lingüística, literatura, composición literaria pero, sobre todo, aprendimos lo más importante; aquello que olvidan enseñar, tal vez porque no lo saben, tantos profesores que se dicen famosos: que a nuestro alrededor hay gente, hombres y mujeres a quienes nos debemos, personas que, "con sus defectos aparentemente ridículos, pueden probar [...] que han nacido pequeñitos, como decía César Vallejo [...], pueden probar que no han tenido nunca nadie que les ayude a crecer". Y sigo las palabras de don Alonso que en todo comparto: Ellos "son los míos. Por ellos y para ellos pienso seguir escribiendo". No he tenido otra España más habitable y tengo que ponerme en limpio todas las mañanas.

También nos lo hizo comprender en su discurso de ingreso en la Real Academia Española: para entender la literatura, muy posiblemente, hay que salir de lo académico. Terminemos aquí, que también dice el refranero: "Sermón, discurso y visita: media horita".

\section{Referencias bibliográficas}

Barthes, Roland (1974): ¿Por dónde empezar?, trad. de F. Llinás. Barcelona: Tusquets.

Papeles de Son Armadans, tomo LXX, núms. CCIX-CCX, agosto-septiembre, 1973.

Rancière, Jacques (2010): La noche de los proletarios. Archivos del sueño obrero, trad. y notas de E. Bernini y E. Biondini. Buenos Aires: Tinta Limón Ediciones.

Urrutia, Jorge (2015): Juguetes de un dios frío. Literatura, historia, ideología. Madrid: Devenir.

Zamora Vicente, Alonso (1966): "Una mirada al hablar madrileño", in Lengua, literatura, intimidad: entre Lope de Vega y Azorín, pp. 63-73. Madrid: Taurus.

Zamora Vicente, Alonso (1967): Asedio a Luces de Bohemia, primer esperpento de Ramón del Valle Inclán. Discurso leído el día 28 de mayo de 1967 en su recepción pública. Madrid: Real Academia Española.

Zamora Vicente, Alonso (1969): "Yo escribo los domingos", in F. Ynduráin (ed.), Prosa novelesca actual [Segunda Reunión, agosto 1968], Universidad Internacional Menéndez y Pelayo, pp. 277-285. [Madrid]: Ministerio de Educación y Ciencia. 